This item was submitted to Loughborough's Research Repository by the author.

Items in Figshare are protected by copyright, with all rights reserved, unless otherwise indicated.

\title{
How people who self-harm negotiate the inpatient environment: the mental healthcare workers perspective
}

\section{PLEASE CITE THE PUBLISHED VERSION}

https://doi.org/10.1111/jpm.12384

\section{PUBLISHER}

(c) John Wiley \& Sons, Inc.

\section{VERSION}

AM (Accepted Manuscript)

\section{PUBLISHER STATEMENT}

This work is made available according to the conditions of the Creative Commons Attribution-NonCommercialNoDerivatives 4.0 International (CC BY-NC-ND 4.0) licence. Full details of this licence are available at: https://creativecommons.org/licenses/by-nc-nd/4.0/

\section{LICENCE}

CC BY-NC-ND 4.0

\section{REPOSITORY RECORD}

Thomas, J.B., and Cheryl Haslam. 2019. "How People Who Self-harm Negotiate the Inpatient Environment: The Mental Healthcare Workers Perspective”. figshare. https://hdl.handle.net/2134/25943. 
How people who self-harm negotiate the inpatient environment: the mental healthcare workers perspective

J . B . THOMAS ${ }^{1} \&$ C. O. HASLAM ${ }^{2}$

${ }^{1}$ Assistant Psychologist, Cumbria Partnership Foundation Trust

${ }^{2}$ Professor of Health Psychology, School of Sport, Exercise and Health Sciences, Loughborough University, Loughborough, UK

Correspondence:

J. B. Thomas

Ann Burrow Thomas Building,

Workington, CA14 2EW

UK

E-mail: j.thomas-10@alumni.lboro.ac.uk 


\section{$\underline{\text { Abstract }}$}

Introduction: Literature describes self-harm as functional and meaningful. This creates difficulties for service-users detained in an inpatient environment where self-harm is prevented.

Aim: Mental-healthcare staff were interviewed to build on existing evidence of issues with the prevention approach and explore, from a staff perspective, how self-harm prevention impacts on service-users, how they manage distress and how this impacts on staff approach to care.

Methods: Qualitative methods were used to allow unexpected themes to arise. Ten semistructured interviews were carried out with mental-healthcare staff and thematically analysed. Findings and discussion: The findings provide new evidence on the benefits and limitations of the inpatient environment for individuals who self-harm. Findings indicate that being unable to self-harm can lead to a continuation of distress and subsequent potentially-harmful attempts to manage distress. Staff described experiencing a struggle for control in preventing self-harm, leading to increasingly harmful methods of self-harm. Alternatively some staff were able to support service-users with distress management. We discuss factors influencing which of these 'paths' service-users followed.

Implications: Considerations for care planning including understanding self-harm, using individualised care-planning and attending to barriers are outlined with the ultimate aim of reducing distress and the impact of prevention of self-harm.

Key Words: Coping, Psycho-social intervention, Self-harm, Staff perceptions, Qualitative methodology. 


\section{Accessible summary}

What is known about the subject?

- Self-harm plays a function, commonly in the form of distress management.

- There has been little focussed exploration of how individuals who use self-harm to manage distress cope when prevented from self-harm in an inpatient environment and how staff respond to this issue.

What this paper adds to existing knowledge.

- This paper uses the experiences of mental-health staff to add to the existing knowledge that self-harm has a functional role and supports the notion that interventions for self-harm should focus on the origins of distress.

- It describes the potential consequences that focussing on prevention of self-harm as opposed to actually managing distress may have on service-users, how staff attempt to manage these consequences and factors that may impact on staff interventions to prevent further distress/harm.

What are the implications for practice?

- The findings suggest that mental-healthcare staff should aim to understand the function of self-harm, use this understanding to develop an individualised care plan with the aim of managing distress and identify barriers to the effectiveness of the interventions so they can be worked around. 


\section{$\underline{\text { Introduction }}$}

Self-harm is an increasingly common behaviour (Hawton et al. 2007; Long, Manketlow \& Tracey, 2013) with an increased clinical and research interest (Harris, 2000). Despite this, self-harm is widely misunderstood (Arnold, 1995; Long et al., 2013) which service-users have identified can lead to unhelpful responses from services and to experiences of feeling ridiculed, isolated, angry and further distress (distress here referring to psychological experiences such as anxiety, hopelessness, worthlessness, depression and sadness, restlessness and tiredness, e.g. Andrews \& Slade, 2001). This may lead to further self-harm and refraining from seeking help in the future (Bywaters \& Rolfe, 2002; Harris, 2000).

Self-harm is the strongest known risk factor for suicide (Sakinofsky, 2000) and is identified as a signal for practitioners to be attentive to possible suicidal ideation (Wyatt \& Gask, 2009). Many definitions suggest that self-harm and suicide are on different points of one continuum, however, reports of fundamental differences between self-harm and suicide suggest that unification of self-harm and suicide is invalid (Cutliffe, Braithwaite \& Stevenson, 2008). Harris (2000) describes that self-harm became acknowledged as a separate phenomenon from suicide in the 1970's which encouraged investigation into how the motivations and functions of self-harm differed to those behind suicide. Evidence shows that a proportion $(20.1 \%)$ of people believe self-harm helps to prevent suicide (SANE, 2008) and is a functional behaviour (Cutliffe et al., 2008; Long et al., 2013).

What do we know about this topic?

Research has typically focussed on developmental risk factors such as childhood sexual (Santa Mina \& Gallop, 1998) and physical abuse (Gratz Conrad \& Roemer, 2002), neglect (Gratz et al., 2000), dysfunctional family backgrounds (Suyemoto, 1998) and attachment 
(Gratz et al., 2002). Linehan (1993) suggests that these invalidating environments fail to provide the child with effective emotion regulation strategies and may lead to the adoption of potentially-harmful coping strategies such as self-harm (Linehan, 1993). As Suyemoto (1990) emphasises, it is these types of underlying psychological difficulty that should be the focus of intervention.

Self-harm is described at length within the academic sphere and by service-users as a functional and "useful strategy in managing overwhelming thoughts and feelings to help someone stay alive in the face of enormous struggle" (Roe, 2013, p.53). Commonly reported functions of self-harm are summarised in table 1. Preventing self-harm has been described in service user literature to sometimes lead to increases in distress and more dangerous/less controlled, forms of self-harm. This has led to scepticism about the effectiveness of prevention (Foster, 2013; Holley, Horton, Cartmail \& Bradley, 2012; Shaw, 2013; Shaw and Spandler, 2007).

This creates difficulties for service-users detained in an inpatient facility where measures are put in place to prevent self-harm. Under the Mental Health Act (2007), this occurs in the interest of their own or other people's safety which is at risk due to mental-health difficulties and allows for staff to carry out assessment and implementation of a care-plan (Joint Commissioning Panel for Mental Health, 2013). 
Table 1: Functions of self-harm

\begin{tabular}{|c|c|c|}
\hline Function & Explanation & References \\
\hline To gain a sense of control & To exert control over the body and one's emotions. & $\begin{array}{l}\text { (Brown \& Beail, 2009; Foster, 2013; } \\
\text { Haines \& Williams, 1997; Harris, } \\
\text { 2000; Miller, 1994). }\end{array}$ \\
\hline Self-punishment & $\begin{array}{l}\text { Self-harm may resolve emotional arousal caused by cognitive } \\
\text { dissonance between what one thinks they deserve (e.g. punishment) } \\
\text { and their current state (e.g. unpunished). }\end{array}$ & $\begin{array}{l}\text { (Briere \& Gil, 1998; Rodham et al., } \\
\text { 2004; Staples, 2013). }\end{array}$ \\
\hline Avoidance / distraction & Physical pain may divert attention away from painful emotions. & (Briere \& Gil, 1998; Crouch \& \\
\hline
\end{tabular}




\begin{tabular}{|l|l|l|}
\hline & & Wright, 2004; Shaw, 2013). \\
\hline To control social boundaries & People may use self-harm in attempt to avoid abandonment. & (Gratz, 2003; Muehlenkamp et al. \\
& & 2013; Suyemoto, 1998). \\
\hline
\end{tabular}


What don't we know and what do we aim to find out?

Little is known about the impact of prevention of self-harm on coping within inpatient environments. Service-users have described the consequential increase in distress and how their self-harm was impacted in response to prevention but limited research has focussed on broader consequences of prevention on distress, how this impacts management of distress within the inpatient environment and the factors that may influence this dynamic. O'Donovan and Gijbels (2006) have reported that psychiatric nurses described prevention and safety as their priority but this may sit in contrast with the needs of service-users. Holley et al. (2012) have described staff's conflicts between their desire to protect the individual alongside an acknowledgement of the distress caused by preventing self-harm. Our work aimed to build on this by hearing the voices of staff on the dilemma whereby prevention has the potential to actually cause harm. It also aimed to explore how staff attempted to influence service-users negotiation of prevention of self-harm within the inpatient environment and identify factors that they saw as influential on their interventions. While staff give a partial perspective on the issue they were able to provide a broad range of insights from their work with service-users of varied backgrounds and functions for their self-harm. They were also able to comment on issues such as those discussed in Holley et al. (2012) from the position of a staff role. Bringing the insights given here together with the existing evidence would give the potential to consider implications for care-planning.

\section{Methods and Methodology}

A qualitative method was chosen in order to avoid making assumptions about how people respond to an inpatient environment. The qualitative method avoids closing any avenue of investigation, in turn allowing unexpected themes to arise (Silverman, 2000).

\section{Participants}

Ten Mental-healthcare staff with an age range from 23-31 (8 females and 2 males) and experience 
of working in an inpatient environment where service-users have been detained under the Mental Health Act (2007) were recruited. The sample included nurses, support workers, assistant psychologists and trainee psychologists with varied experiences (including forensic, rehabilitation, substance misuse, acute, low/medium/high secure, specialist physical health and older adult inpatient services) acquired through existing contacts.

\section{Procedure}

An interview schedule was designed with open ended questions to avoid imposing ideas on the interviewee and to allow them to develop their own thoughts (Willig, 2008). A focus group was held with a clinical psychology team from an inpatient facility in order aid development of the interview schedule. This involved reflecting on how to introduce the study, the types of questions used, the information they would elicit and how the researcher's own preconceived ideas may influence the interview schedule (e.g. how assumptions about self-harm as functional and meaningful may influence questions asked). The schedule was then tested in a pilot interview and modified based on the feedback.

The interviews were carried out over the phone in the interest of pragmatism considering the participants work patterns and other obligations (e.g. child-care). Ideally interviews would have been face-to-face considering the emotive subject however many participants described being unable to attend face-to-face. Interviews were conducted by a male BSc student with experience in qualitative methods and experience of working in an inpatient mental-health facility, supervised by a university based researcher with extensive experience of qualitative research. The interviews lasted between 30 minutes and 2.5 hours, gave a description of the aims of the research and asked about:

- The roles of the participants in their occupation

- Their experiences with service-users who were accessing care in the inpatient mental health 
facilities and who used self-harm to manage distress.

- How they managed/intervened in their role and how the management/intervention effected the service-users they worked with at a psychological and behavioural level.

\section{Data analysis and reflexivity}

In attempt to achieve rigor, audio recordings were transcribed verbatim, transcripts were given a pseudonym to maintain confidentiality and the process of thematic analysis was completed following the guidelines of Braun and Clarke (2006) by the two authors until data saturation was reached. Analyses were shared and reflected on within a small research team in order bring together multiple perspectives and ensure development of themes that captured the data well. Our study took the following approaches to the data as described in Braun and Clarke (2006):

- a theoretical/deductive approach - this meant that the sampling and analysis was driven by the research interests and acknowledged previous research

- a semantic approach by searching for themes at an explicit, surface level and describing patterns in the data whilst using interpretation to theorise the significance and implications in relation to previous research

- an essentialist/realist epistemology, assuming that language adequately reflects meaning and experience

The authors acknowledge that the interviews and analysis were guided by the existing evidence of self-harm as functional and meaningful and thus the interpretation of the data and subsequent themes will reflect existing ideas and may be at risk of neglecting other possible themes. Additionally, participant acquisition through existing contacts could have impacted on the interviews and possibly led to demand characteristics such as seeking to help the perceived needs of the researcher

\section{$\underline{\text { Ethics }}$}

Following ethical clearance from Loughborough University, individual interviews were carried out. 
All participants were given an information sheet outlining ethical procedures, were asked if they wished to proceed with the interview and advised that they could withdraw at any time.

\section{Findings}

Thematic analysis led to the development of five themes. Each theme contained a number of subthemes which are illustrated in Figure 1. 


\section{Characteristics of the inpatient environment in relation to self-harm}

\subsection{Prevention}

Mental-healthcare staff spoke of various ways in which self-harm is prevented. People of all professions aimed to prevent self-harm prospectively using methods such as psycho-education and therapies. Other prospective approaches included observation, limiting access to risk items and recognising and responding to indicators of heightened distress. Physical restraint was used if someone was going to self-harm.

\subsection{Benefits of the inpatient environment}

The inpatient environment was described as a place in which staff could provide consistent care, allowing service-users who experienced urges to self-harm to receive prolonged care that aided them in overcoming urges to self-harm.

Emily - "If we can distract somebody from that 10 minute urge [...] we can then stop them for an hour and then we can stop them for 2 hours and then 3 hours and then we can just keep intervening”.

The inpatient environment was appreciated for being a safe environment, in which self-harm can be prevented from becoming life threatening, however participants described being unable to prevent all self-harm.

Jamie - "But at the end of the day you can't be there 100\% of the time to restrict that because it can be over and done with in a second".

\subsection{Limitations of the inpatient environment}

Whilst the inpatient environment was appreciated for keeping service-users safe, it was 
acknowledged that this minimised internal locus of control, which may reduce self-belief in the service-user of being able to survive without self-harm.

Kirsty - "I guess in some ways it takes away, or can run the risk of taking away responsibility, so the control of self-harm becomes externalised".

Another limitation of the inpatient environment was that it may expose service-users to distressing incidents on the ward. For a person who manages distress using self-harm, this was acknowledged as being a distressing experience which could be a trigger for self-harm.

Rachael - "There was an incident where a lady had cut her arms [...] and of course that makes them think of self-harm which might trigger some of their problems”.

Prevention methods are used to prevent self-harm, however these measures were recognised to potentially hinder quality of life $(\mathrm{QoL})$. This gave rise to a consideration of whether physical health through prevention of self-harm should be prioritized above QoL.

Kirsty - "if somebody does end up self-harming, because you've taken that positive risk [...] there are other advantages to it [...] if they don't take those positive risks their QoL is potentially going to be horrible anyway”.

Emily - “The first thing you do with a service-user isn't actually discharge plan and recovery, it is risk management and that's where I actually think we fail people”.

\section{Experiences of distress and urges to self-harm in the inpatient environment}

Staff described their observations of service-users' experiences of distress within the inpatient 
environment and how the inpatient environment influenced their levels of distress.

\subsection{Self-harm urges as background noise that intensifies, reaching a climax that must be endured or managed.}

The urge to self-harm was perceived for some people to be a constant background urge that intensified at times, leading to a climax that could no longer be tolerated.

Emily - "Evening times are the worst [...]. A lot of these girls have very racing thoughts, they had a lot of trauma [...] and they've coped with whatever is going on all day and they either can't take it anymore”.

\subsection{Continuation of distress/becoming more distressed as a result of not being able to self-} harm

Participants described that once the background urges to self-harm became more intense, being prevented from self-harming often led to a continuation in distress and could damage the therapeutic relationship.

Rachael - "They would blame you with not allowing them to self-harm, blame you for that intense feeling to last longer because they haven't been able to cut it short themselves”.

Staff described prevention of self-harm could provoke responses of aggression, withdrawal from care and isolation, which can be understood due to the service-users continued distress.

Rachael - "either you get someone be hostile and aggressive [...] because you're preventing someone from doing what they want [...] Or you get somebody completely withdraw into themselves or completely disengage from any help, any talking”. 


\section{When the inpatient environment doesn't provide service-users with means of managing}

\section{distress.}

In the context of prevention of self-harm leading to a continuation of service-users distress, staff described two 'paths' in which service-users attempted to manage this distress within the inpatient environment. On the one hand, a process where self-harm had not been successfully replaced by other means of distress management and service-users thus attempted to find their own methods of distress management was described. On the other hand, participants also described a process in which the inpatient environment provided a successful means of managing distress. This theme outlines the first path.

\subsection{Patients being motivated to find other ways of avoiding distress}

In the context of unappeased psychological distress, staff described how service-users sought to manage distress within the inpatient environment. They described that without supporting the individual through the distress they experienced due to prevention of self-harm, the service-user may be motivated to find other ways to self-harm that would circumvent prevention measures.

Kirsty - "there will be some occasions where being in that setting isn't actually reducing their urge to self-harm, so that urge is still there and they've not learnt any strategies that have been suitable for them [...] then you will just find that they find sly other ways”.

One of the most frequent ways service-users self-harmed within the inpatient environment was to construct or find objects that they could self-harm with.

Ian - "He'd got the top of the head and shoulders shampoo bottle, snapped the top off, snapped it in half and he'd been cutting his arm". 
This dynamic led to a struggle for control between staff and service-users, in which service-users found a way to self-harm within the inpatient environment and staff responded by implementing further prevention measures, to which service-users find yet another way to self-harm. This sometimes meant that service-users would move on to more dangerous methods of self-harm that were more accessible such as restricting eating, swallowing foreign objects and inserting.

Lisa - "A girl that we worked with for a long time who we prevented from self-harming stopped eating and it was out of our hands [...] and next thing with someone that started NG feeding it then became head banging”.

Various other forms of self-harm that occurred in the inpatient environment included burning, biting, re-opening wounds, self-neglect, overeating, and scratching. These methods of self-harm occurred at opportune times when prevention measures were relaxed such as meal times, evenings, and when staff were absent.

Another practice that was used by service-users to manage distress was the use of sleep, medication to induce sleep, use of PRN medication, legal highs and illegal drugs in attempt to avoid experience of distress.

Emily - “That comes into our substance misuse, and that isn't just your bog standard legal, illegal, alcohol, it's also inpatient drugs, they'll use inpatient drugs to cope [...] which is a help and a hinder because it covers them up (negative emotions) but it doesn't deal with them".

Lisa - "Some people have a habit of going to sleep because if they can sleep then they can't do anything to themselves, so they feel safer". 


\subsection{Maintenance of self-harming}

The accounts given by the staff provide a narrative in which self-harm is a reliable distress management technique for some service-users which is often resorted to.

Katie - "Oh yeah, she'd go completely calm, like, she wouldn't keep trying to do it would she, like she'd got that relief”.

These descriptions by the mental-healthcare staff describe why self-harm may be repeatedly depended on. However, self-harm was also observed to maintain distress for some people by leading to feelings of guilt.

Beth - "If people don't self-harm they feel really distressed [...] but even if they do manage to self-harm it's “oh god, I'm a terrible person”."

Negative staff responses to self-harm were also recognised to be a possible maintenance factor for distress and self-harm.

Beth - "sometimes responses from staff can be quite punitive, then they can maintain the behaviours and maintain the distress".

4. Ways that the inpatient environment attempts to displace self-harm by providing service-users with alternative means of managing distress

4.1. Use of psychological techniques, medication and other resources to cope with distress as opposed to using self-harm

Service-users often approached staff for support as an alternative to using self-harm, but this was 
dependent on the therapeutic relationship and whether support was available.

Emily - "back to the trust about patients seeking out staff they will feel comfortable selfharming and ringing their bell with for instance. If they've not built up that trust [...] they may not do that”.

Dialectical behaviour therapy (DBT) and Mindfulness were frequently employed, however, participants acknowledged that these approaches didn't provide immediate relief and required practice.

Beth - "It's about recognising what the function of the behaviour is and trying to think of other ways that those needs can be met."

Beth - "Sometimes those mood strategies are quite difficult to implement and they don't get the reinforcement as quickly".

Kirsty - "a lot of people find those to be effective [...] normally it's when they've been through a cycle a couple of times and the skills have become [...] more automatic”.

Distraction was also used by staff and was described as valuable when a service-user had not been able to consolidate use of other skills. Social support was experienced by many participants as helpful.

Emily - "You can stop some self-harming acts by physically saying to someone, or patting them on the shoulder and saying to someone "it's okay, you're safe, no-one's going to hurt you here"”. 


\subsection{Learning of one's ability to cope without self-harm as a result of the inpatient environment.}

One participant described that service-users would use alternative means of managing distress as a result of self-harm being less accessible in the inpatient environment. This was appreciated as possibly providing service-users with the realisation that they can survive their distress without selfharming.

Kirsty - "There's been the odd person where it's shown them that they have been able to survive, because they've not been able to self-harm, they've found that the feeling did go and it's kind of been a learning experience”.

\subsection{Harm-minimisation}

The concept of harm-minimisation was considered as one way the inpatient environment could support service-users in the management of their distress. Staff described several concerns with the safety and consequences of harm-minimisation.

Rachael - "One extra hard cut or something to go wrong and it's no longer safe”.

Katie - "I don't think there was any way you could give her, probably, the level of self-harm she'd want".

Lisa - "I don't know whether that would just escalate things in the long term”.

\section{Variables that influence responses to the inpatient environment}

Theme 5 describes the factors observed to influence whether the interventions provided by staff 
were successful or whether the individuals staff worked with felt the need to meet their psychological needs using their own methods.

\subsection{Individual differences}

Age and gender were described as influences on how service-users responded to interventions. Older/more experienced service-users were described as more able to master alternative psychological techniques.

Lisa - "It's the older patients, the patients who have gone through self-harming who have been a lot more amenable to different techniques".

Kirsty - "normally it's when they've been through a cycle a couple of times and the skills have become [...] more automatic".

Additionally, responses to being unable to self-harm were reported to be influenced by gender.

Ian - "Men do tend to act out in rage against each other [...]. The women tend to, from my experience, use objects against themselves”.

\subsection{Circumstantial differences}

Responses to interventions within the inpatient environment were described as being influenced by the circumstances that led to their distress. Some circumstances may be experienced by serviceusers as especially distressing and they may feel unable at their point in recovery to manage this distress using alternative strategies.

Jamie - "Some people it's very hard, some people it's very easy to bring round depending on 
the circumstance that's led to them feeling that way”.

\subsection{Therapeutic relationship}

The therapeutic relationship was identified as an influence on whether or not a service-user would feel comfortable seeking support.

Emily - "(Interviewer: So, does that person come and make you aware that they've got those urges at that time?). That would again depend on your therapeutic relationship[...] we build relationships with somebody, therapeutic relationships to the point where somebody trusts you, now that person will trust you and confide in you".

\subsection{Staff resources}

The resources and staff available to service-users was also recognised to influence whether they would seek support from staff.

\subsection{Readiness to change and broader psychological health}

Service users' readiness to stop self-harming and their psychological strength at that point in time were considered to be factors that influenced the success of staff interventions.

Rachael - "If that individual is strong enough to not want to self-harm in the first place [...] using a distraction technique would help, but if that person isn't strong enough [...] those distraction techniques won't work".

\subsection{Other service-users}

Other service-users were thought to influence how service-users responded to the inpatient environment. For example, one person self-harming could trigger other service-users to want to do 
the same thing. 
Fiq. 1 - The dark arrows show the links between themes and subthemes. The lighter coloured arrows demonstrate links between themes. The dotted arrows illustrate influence of one theme on another. The link between subtheme 1 and theme 2 illustrate how prevention of self-harm led to experiences of continued distress.

The links between theme 2 to themes 3 and 4 show the categories of responses to this continued distres

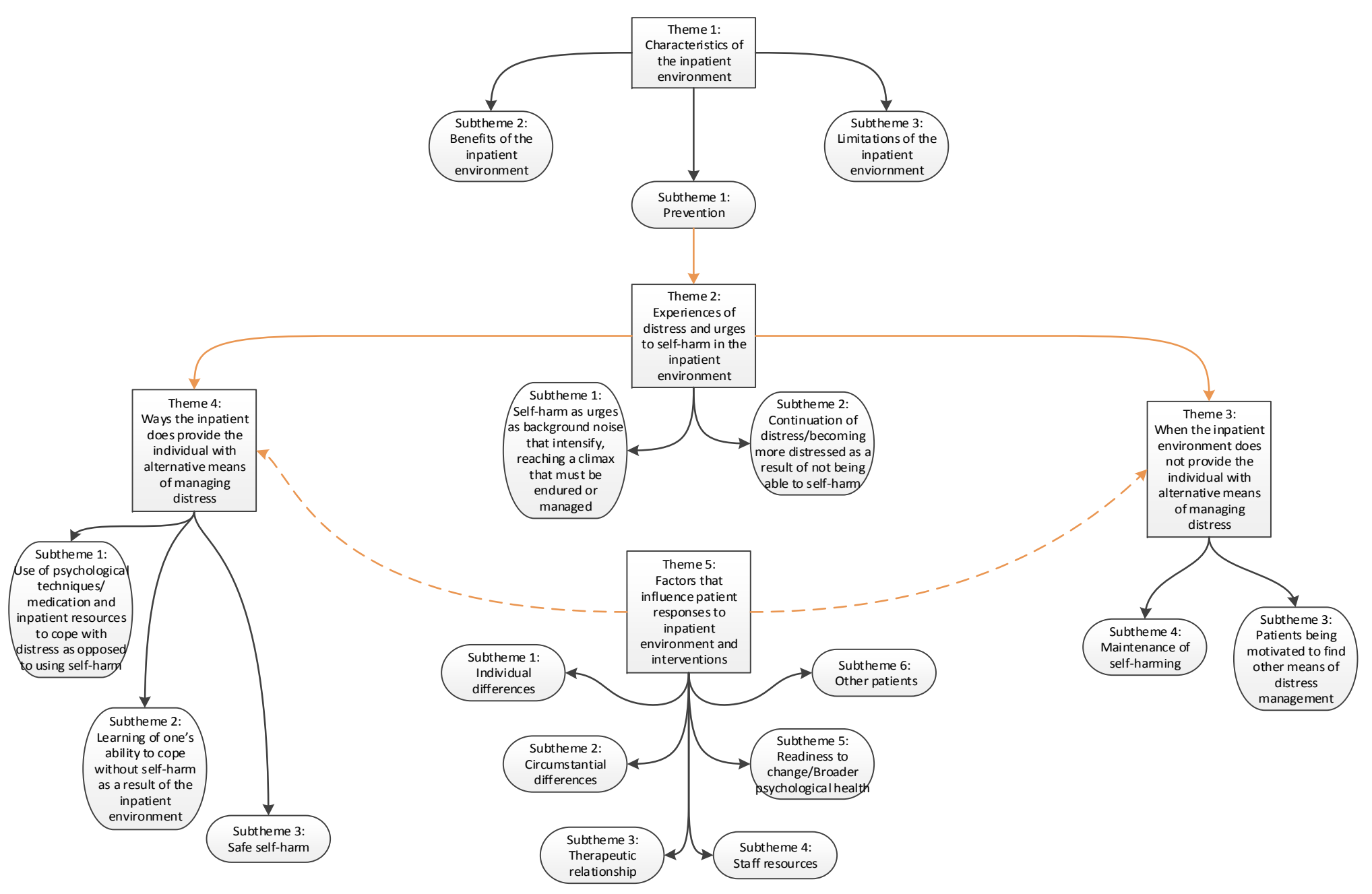




\section{$\underline{\text { Discussion }}$}

What the study adds to the existing evidence

This is the first study to investigate how being detained in an inpatient environment impacts the management of distress in service-users who use self-harm as a primary method of distress management from a staff perspective. Five key findings were developed, which are reflected in the themes described and build on existing evidence. They provide new insights into the impact of prevention of self-harm on service-user distress, how staff try to intervene in this dynamic and factors they recognised to influence their interventions.

Firstly, the inpatient environment was described by staff with their perspective on how self-harm was prevented and how this could impact service-users. Recognition that QoL may be diminished through prevention measures reflected the broad prioritisation of physical health as described in O'Donovan and Gijbels (2006) but added the consideration of how this impacted QoL. This insight reflected a narrative which has been identified in some experiences of the inpatient environment as potentially nontherapeutic (Evans, 2013; Holley et al., 2012) by focussing on risk and self-harm as opposed to mental-health.

Secondly, participants described that when unable to self-harm, service-users were observed to experience increased/continued distress as a result of not being able to selfharm. This is reflective of service-users/carers descriptions where prevention of selfharm has increased/continued distress (Evans, 2013; Foster, 2013; Holley et al., 2012; Shaw \& Spandler, 2007). Participants enhanced the description of this dynamic with their observations of the consequences of this continued distress and descriptions of how it impacted their relationship with the individual through being blamed for causing 
that continued distress.

The third finding was that if the increased/continued distress was not understood and managed well, service-users would be motivated to find another way to manage their distress. This occurrence was reflected upon by Winship (2013) who suggested the aim of staff should be to supersede the need for physical intervention through enabling service-users to express what they are feeling before they come to self-harm. Our findings complemented this idea by conversely describing that punitive responses to distress maintained self-harm. The perspective of staff gave insight into the progressing struggle staff had for control that occurs as a result of service-users' search to find other ways of self-harming which often increases risk through use of methods such as starvation and swallowing. Staff understood the resulting self-harm and distress as being maintained through unhelpful staff responses but also noticed the resulting distress of having self-harmed. This is reflective of the cycle of self-harm, experience of rejection resulting in shame and guilt and further self-harm described by Rayner and Warne (2015). This study also added the insight of staff's observations of the ways distress management was achieved using medication, other drugs and through sleep (as previously described in Huband and Tantam [2004]). Chapman et al. (2006) have warned of the adoption of such behaviours aimed at avoidance of distress as they may be effective for short-term release, but are likely to result in a long-term maintenance of distress.

The fourth finding pertains to the inpatient environment successfully aiding serviceusers to manage their distress. The interviews described use of psychological techniques and social support. Again, this was reflective of Winship's (2013) encouragement of 'mental holding' to better recognise distress early and facilitate understanding and 
expression so that the individual feels heard. These findings supported Suyemoto's (1990) theorising that, in order to reduce self-harm, interventions should target the primary issues that are leading to self-harm. Harm-minimisation in which self-harm was allowed was one approach staff had used to manage distress. Our findings raised concerns about increased distress and self-harm that occur with 'the prevention approach' as also described in Foster (2013), Shaw (2013) and Holley et al. (2012) and added insight into how staff can be drawn into a struggle for control that can counterproductively increase risk. This raises considerations of who carries the risk with regards to self-harm when prevention is potentially increasing risk. Use of harmminimisation approaches have been shown to reduce overall incidence of self-harm and staff anxiety (Holley et al., 2012) and to promote personal responsibility (Denison, 2013; Evans, 2013). However, participants in the present study described several concerns about safety and consequences of harm-minimisation. Finding less potentiallyharmful strategies for distress management is the ideal but our findings outlined possible barriers to the success of such interventions such as service users' readiness for change. This mirrors the accounts of service-users who describe that only they could have stopped their self-harm when they were ready to (Evans, 2013). Opposing this experience though, one staff member described working with individuals who had learned that they could survive without self-harm through being prevented from selfharming.

The final findings provide insight into to the factors felt to have impacted the success of staff's interventions. The therapeutic relationship was one factor that is recognised as important in the success of interventions. It has been described by Long and Jenkins (2010) as important due to the sensitive nature of the underlying issues and the stigma around self-harm, which require a high level of trust to approach staff to talk about these 
issues. Our findings give new insights into the interactions of these factors. For example, participants described how links between factors such as therapeutic relationship and staff availability could impact whether a person would seek support. Factors such as experience with alternative methods of distress management suggest that repeatedly supporting people in using them may be helpful.

\section{$\underline{\text { Implications and recommendations for practice }}$}

We recommend three broad areas of consideration that should be reflected upon in careplanning for individuals who self-harm but are prevented from doing so through detention to an inpatient facility.

\section{Understanding the underlying distress}

“Self-harm happens for a reason and everybody's reasoning for self-harm is and will always be different" (Shortland, 2013, p.29). The findings here reflect the importance of understanding and attending to the individual's reason for self-harm by illustrating that failure to do so may lead to use of other potentially harmful methods of distress management. Exploration of the functions and meaning of self-harm could be carried out by any staff-member with a good relationship. Practically, this may include exploring self-harm as guided by Wyatt and Gask (2008):

- The events preceding self-harm

- What these events meant to the individual

- The amount of planning that went into the self-harm and how this may influence care planning (e.g. impulsive self-harm may warrant a different approach to management than planned self-harm).

- The expected outcome of self-harm

- How the person felt after the self-harm and what function it fulfilled 
2. Individualising interventions based on this understanding

Individualised care planning that acknowledges idiosyncrasy would help to identify the most helpful interventions for averting a continuation of distress and use of harmful ways of managing distress. This could involve use of tools such as 'The Choice Model' (Y.K., 2013) which seeks to identify the need behind self-harm urges and then find lessharmful ways to meet these needs.

\section{Identifying and working around barriers to intervention}

Participants described the importance of factors such as therapeutic relationship and readiness for change when evaluating the effectiveness of an intervention. Staff should be mindful of these and try to find solutions when creating an individualised care plan for individuals who self-harm and have been detained. For example, supporting individuals during early use of alternative techniques may help to overcome the barrier of having yet to master the technique.

\section{Limitations and future research}

The use of mental-healthcare staff, while providing a broad range of experience, does not provide first-hand experience of managing distress within the inpatient environment. We believe research accessing the more personalised experiences of service users would go hand in hand with this research and would be of value considering the lack of research on the value of psycho-social interventions from the service-users' perspective (Ward, de Motte and Bailey, 2012). Secondly, the small sample and qualitative approach limits the generalisability of these findings.

Future research could also explore the extent to which being prevented from self- 
harming was observed to provide the experience of being able to survive distress without self-harming but could also discourage internal control of self-harm.

Triangulation of the findings presented using trust policy contributors, service-users and their families would access some of the important voices in this debate.

\section{Conclusion}

This study has provided new insights into how service-users, with a history of selfharm, respond to prevention of self-harm when in the inpatient environment. The study identified staff perceptions of how service-users attempted to manage their distress in the inpatient environment and described staff experiences of trying to help service-users utilise the resources provided by the inpatient environment to manage distress. 


\section{$\underline{\text { References }}$}

Andrews, G., \& Slade, T. (2001). Interpreting scores on the Kessler Psychological Distress scale (k10). Australian and New Zealand Journal of Public Health, 25, 494-497.

Arnold, L. (1995). Women and self-injury: A survey of 76 women. A report on women's experience of self-injury and their views on service provision. Bristol; Bristol Crisis Service for Women.

Baker, C., Shaw, C., \& Biley, F. (2013). Our Encounters with Self-Harm. Monmouth: PCCS Books.

Braun, V., \& Clarke, V. (2006). Using thematic analysis in psychology. Qualitative Research in Psychology, 3(2), 77-101.

Briere, J., \& Gil, E. (1998). Self-mutilation in clinical and general population samples: Prevalence, correlates and functions. American Journal of Orthopsychiatry, 68(4), 609-620.

Brown, J., \& Beail, N. (2009). Self-harm among people with intellectual disabilities living in secure service provision: A qualitative exploration. Journal of Applied Research in Intellectual Disabilities, 22(6), 503-513.

Bywaters, P., \& Rolfe, A. (2002) Look beyond the scars: Understanding and responding to self_-injury and self-harm. London: $\mathrm{NCH}$ and Centre for Social Justice. 
Chapman, A. L., Gratz, K. L., \& Brown, M. Z. (2006). Solving the puzzle of deliberate self-harm: The experiential avoidance model. Behaviour Research and Therapy, 44(3), 371-294.

Connors, R. (1996). Self-injury in trauma survivors: 1. Functions and meanings. American Journal of Orthopsychiatry, 66(2), 197-206.

Crouch, W., \& Wright, J. (2004). Deliberate self-harm at an adolescent unit: A qualitative investigation. Clinical Child Psychology and Psychiatry, 9(2), 185204.

Cutliffe, J. R., Braithwaite, D.G., \& Stevenson, C. (2008). A critique of Anderson and Jenkins' article: 'The national suicide prevention strategy for England: The reality of a national strategy for the nursing profession'. Journal of Psychiatric and Mental Health Nursing, 15(2), 154-160.

Denison, S. (2013). My encounters with self-harm. In: Baker, C., Shaw, C., \& Biley, F. (2013). Our Encounters with Self-Harm. Monmouth: PCCS Books.

Evans, N. (2013). Working through self-harm. In: Baker, C., Shaw, C., \& Biley, F. (2013). Our Encounters with Self-Harm. Monmouth: PCCS Books.

Foster, L. (2013). Self-harm and suicide: Doubts and dilemma's. In: Baker, C., Shaw, C., \& Biley, F. (2013). Our Encounters with Self-Harm. Monmouth: PCCS Books. 
Gratz, K. L. (2000). The measurement, functions and etiology of deliberate self-harm. Unpublished master's thesis, University of Massachusetts, Boston.

Gratz, K.L., Conrad, S. D., \& Roemer, L. (2002). Risk factors for deliberate self-harm among college students. American Journal of Orthopsychiatry, 72(1), 128-140.

Gratz, K. L. (2003). Risk factors for and functions of deliberate self-harm: An empirical and conceptual review. Clinical Psychology: Science and Practice, 10(2), 192205.

Haines, J., \& Williams, C. (1997). Coping and problem solving of self-mutilators. Journal of Clinical Psychology, 53(2), 177-186.

Harris, J. (2000). Self-harm: Cutting the bad out of me. Qualitative Health Research, 10(2), 164-173.

Hawton, K., Bergen, H., Casey, D., Simkin, S., Palmer, B., Cooper, J., ... Owens, D. (2007). Self-harm in England: A tale of three cities. Multicentre study of selfharm. Social Psychiatry and Psychiatric Epidemiology , 42(7), 513-521.

Holley, C., Horton, R., Cartmail, L., \& Bradley, E. (2012). Self-injury and harm minimisation on acute wards, Nursing Standard, 26(38), 51-56.

Huband, N., \& Tantam, D. (2004). Repeated self-wounding: Women's recollection of pathways to cutting and of the value of different interventions. Psychology and Psychotherapy: Theory, Research and Practice, 77, 413-428. 
Joint Commissioning Panel for Mental Health, (2013). Guidance for commissioners of acute care - inpatient and crisis home treatment. Retrieved July 24, 2016, from http://www.jcpmh.info/wp-content/uploads/jcpmh-acutecare-guide.pdf.

Klonsky, E. D., \& Muehlenkamp, J. J. (2007). Self-injury: A research review for the practitioner. Journal of Clinical Psychology, 63(11), 1045-1056.

Linehan, M. M. (1993). Cognitive-behavioural treatment of borderline personality disorder. New York, NY: Guilford Press.

Long, M., \& Jenkins, M. (2010). Counsellors' perspectives on self-harm and the role of the therapeutic relationship for working with clients who self-harm. Counselling and Psychotherapy Research, 10(3), 192-200.

Long, M., Manktelow, R., \& Tracey, A. (2013). We are all in this together: Working towards a holistic understanding of self-harm. Journal of Psychiatric and Mental Health Nursing, 20(2), 105-113.

Low, G., Jones, D., MacLoed, A., Power, M., \& Duggan, C. (2000). Childhood trauma, dissociation and self-harming behaviour: A pilot study.

Mangnall, J., \& Yurkovich, E. (2008). A literature review of deliberate self-harm. Perspectives in Psychiatric Care, 44(3), 175 -184.

Miller, D. (1994). Women who hurt themselves. New York, NY: Harper Collins. 
Muehlenkamp, J., Brausch, A., Quigley, K., \& Whitlock, J. (2013). Interpersonal features and functions of nonsuicidal self injury. Suicide and Life-Threatening Behavior, 43(1), 67-80.

O’Donovan, A., \& Gijbels, H. (2006). Understanding psychiatric nursing care with nonsuicidal self-harming patients in acute psychiatric admission units: The views of psychiatric nurses. Archives of Psychiatric Nursing, 20(4), 186-192.

Peacock,R.L.(2013). Self-harm. In: Baker, C., Shaw, C., \& Biley, F. (2013). Our Encounters with Self-Harm. Monmouth: PCCS Books.

Rayner, G., \& Warne, T. (2015). Interpersonal processes and self-injury: a qualitative study using bricolage. Journal of Psychiatric and Mental Health Nursing, 23(1), $54-65$.

Rodham, K., Hawton, K., \& Evans, E. (2004). Reasons for deliberate self-harm: comparison of self-poisoners and self-cutters in a community sample of adolescents. Journal of the American Academy of Child and Adolescent Psychiatry, 43(1), 80-87.

Roe, C. (2013). P.S. ... Help me. In: Baker, C., Shaw, C., \& Biley, F. (2013). Our Encounters with Self-Harm. Monmouth: PCCS Books.

Sakinofsky, I. (2000). Repetition of suicidal behaviour. In K. Hawton \& K. van Heeringen (Eds.), The international handbook of suicide and attempted suicide (pp, 385-404). Chichester, NH: Wiley. 
SANE. (2008). Understanding self-harm. Retrieved from: http://www.sane.org.uk/Research/SelfHarmIntro

Santa Mina, E. E., \& Gallop, R. M. (1998). Childhood sexual and physical abuse and adult self-harm and suicidal behaviour: A literature review. Canadian Journal of Psychiatry, 43(8), 793-800.

Shaw, T. (2013). From ignorance to understanding. In: Baker, C., Shaw, C., \& Biley, F. (2013). Our Encounters with Self-Harm. Monmouth: PCCS Books.

Shaw, C. (2013). 'I do not believe in silence': Self-harm and childhood sexual abuse. In: Baker, C., Shaw, C., \& Biley, F. (2013). Our Encounters with Self-Harm. Monmouth: PCCS Books.

Shaw, C., \& Spandler, H. (2007). A Dialogue of Hope and Recovery in S. Warner \& H. Spandler (Ed.), Beyond Fear and Control: working with young people who selfharm (pp. 28-29). Ross-on-Wye: PCCS Books.

Shortland, C. (2013). Fight for life. In: Baker, C., Shaw, C., \& Biley, F. (2013). Our Encounters with Self-Harm. Monmouth: PCCS Books.

Staples,T. (2013). To whom it may concern. In: Baker, C., Shaw, C., \& Biley, F. (2013). Our Encounters with Self-Harm. Monmouth: PCCS Books.

Suyemoto, K. L. (1998). The functions of self-mutilation. Clinical Psychology Review, 
18(5), 531-554.

Ward, J., de Motte, C., \& Bailey, D. (2012). Service-user involvement in the evaluation of psycho-social intervention for self-harm: A systematic literature review. Journal of Research in Nursing, 18(2), 114-130.

Willig, C. (2008). Introducing qualitative research in psychology. Berkshire, England: Open University Press.

Winship, G. (2013). Self-injured therapists encountering self-harm. In: Baker, C., Shaw, C., \& Biley, F. (2013). Our Encounters with Self-Harm. Monmouth: PCCS Books.

Wyatt, R. C., \& Gask, L. (2009). Instructors manual for suicide and self-harm: Helping people at risk with Linda Gask, MD. Retrieved July 23, 2016, from http://www.psychotherapy.net/data/uploads/51193aec18406.pdf.

Y.K. (2013). The need behind the urge. In: Baker, C., Shaw, C., \& Biley, F. (2013). Our Encounters with Self-Harm. Monmouth: PCCS Books. 